\title{
Edward Welch, François Mauriac. The Making of an Intellectual
}

\section{Emanuele Kanceff}

\section{(2) OpenEdition \\ 1 Journals}

\section{Edizione digitale}

URL: https://journals.openedition.org/studifrancesi/46240

DOI: 10.4000/studifrancesi.46240

ISSN: 2427-5856

\section{Editore}

Rosenberg \& Sellier

\section{Edizione cartacea}

Data di pubblicazione: 1 octobre 2007

Paginazione: 474

ISSN: 0039-2944

\section{Notizia bibliografica digitale}

Emanuele Kanceff, «Edward Welch, François Mauriac. The Making of an Intellectual», Studi Francesi

[Online], 152 (LI | II) | 2007, online dal 30 novembre 2015, consultato il 24 novembre 2021. URL: http:// journals.openedition.org/studifrancesi/46240 ; DOI: https://doi.org/10.4000/studifrancesi.46240

Questo documento è stato generato automaticamente il 24 novembre 2021.

\section{(c) (i) (9)}

Studi Francesi è distribuita con Licenza Creative Commons Attribuzione - Non commerciale - Non opere derivate 4.0 Internazionale. 


\title{
Edward Welch, François Mauriac. The Making of an Intellectual
}

\author{
Emanuele Kanceff
}

\section{NOTIZIA}

EDWARD WELCH, François Mauriac. The Making of an Intellectual, Amsterdam-New York, Rodopi, 2006 (Coll. “Faux Titre", 290), pp. 202.

L'autore di questo studio parte dalla constatazione che, negli anni Cinquanta del Novecento, Mauriac è quasi improvvisamente diventato un influentissimo personaggio in Francia in quanto fra i più seguiti e rispettati commentatori politici, e ciò non grazie alle sue teorie politico-sociali, come era avvenuto di altri suoi noti colleghi scrittori. In effetti, a partire dall'attribuzione del Premio Nobel, se non già prima, la sua carriera di scrittore aveva subito un cambiamento che lo aveva portato a preferire lo scritto giornalistico al racconto romanzato, ed è questa attività giornalistica che in primo luogo si analizza in questo libro. Il cambiamento di Mauriac è in molta parte dovuto, secondo l'autore, ai legami sorti con «L'Express», periodico cui egli si dedicò con fervore per oltre sette anni, attività che aveva per scopo di produrre una modernizzazione e delle riforme della società francese. La sua abituale rubrica, i Blocnotes, volle essere, nelle intenzioni di Mauriac, un asse portante di questo ammodernamento socio-politico. Questa posizione emblematica di intellettuale impegnato e politicamente influente contrasta singolarmente con quanto pareva essere il pensiero dello scrittore negli anni Trenta, all'epoca in cui esprimeva totale indifferenza verso gli intellettuali impegnati nella politica. Ciò ha convinto E. Welch dell'utilità di indagare sull'evoluzione di Mauriac come giornalista, soprattutto nel dopoguerra e particolarmente negli anni Cinquanta e Sessanta, quando nacquero quegli scritti che solo nel 1993 hanno conosciuto la loro edizione critica ad opera di Jean Touzot. L'autore mostra anche l'evoluzione delle idee di Mauriac, passato da un sicuro conservatorismo a concezioni molto più liberali e progressiste. Queste vicende sono 
messe in relazione con le fortune letterarie di Mauriac e con la crescita e il declino della sua fortuna presso il pubblico. 